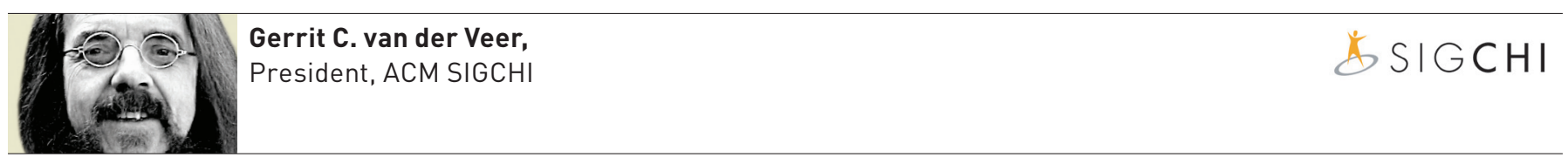

\title{
See You Next Year in Seoul
}

In the past few years, we have seen a steady increase in Korean participation at SIGCHI events. In February I attended HCI Korea 2014, an annual conference that in recent years has drawn around 2,000 participants. This meeting takes three days and includes about 10 parallel tracks. Some of the sessions are in English, easily filling up rooms for more than 500 attendees.

The Korean HCI Society has about 700 members. Many of them have jobs in industry, from Korea-based multinationals to Internet portals, and from large mobile-device and game companies to app companies, which are often small start-ups. Seoul, with 10 million inhabitants, has more than 50 universities. HCI is a core component in business schools, computer science, electrical engineering, communications, and various branches of design.

Seoul is an interesting city to visit. You will find historic palace complexes and Buddhist temples right next door to high-tech companies and tall apartment buildings. I was amused by the interactive toilets that seem to be standard in four- and five-star hotels, as are the mobile devices that control heating, alarms, television, and the many light fixtures - providing puzzles where technology is a challenging partner. Traveling in Seoul and to the airport is easy for those who are used to North American cities: English is a standard language for cabs, as well as for all shops and hotels in the Gangnam district, and the metro map is bilingual.

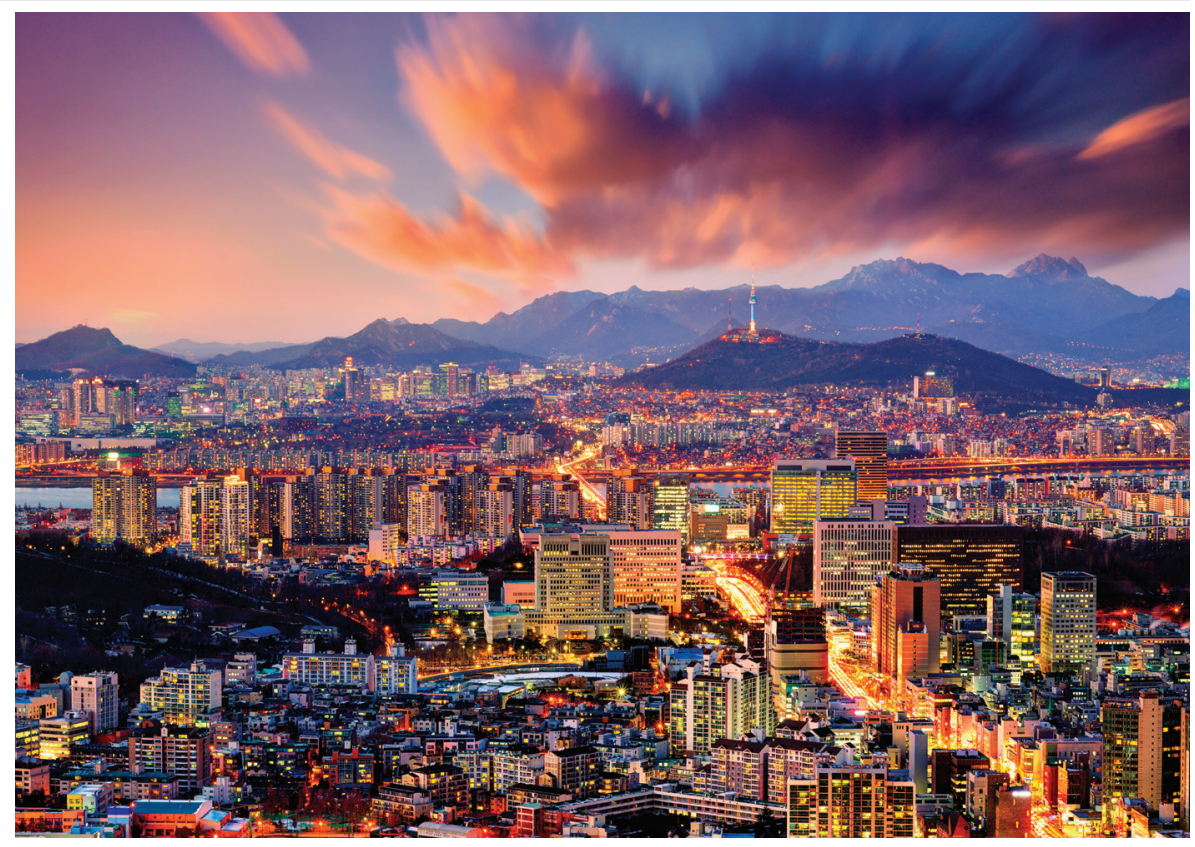

Consequently, next year's CHI conference in the COEX Centre in Gangnam, Seoul, will be a mixture of our flagship conference as we all know it and the local flavor of a booming new modern city where Eastern elegance is paired with advanced technology. Korean food is delicious, and dishes in Korean restaurants are designed to be looked at as much as tasted, but Western food can be found there as well. For participants with a tight budget, cheaper but decent hotels can be reached by metro, and students will find opportunities to mingle with local students and be hosted in their homes.

The CHI 2015 conference chairs,
Jinwoo Kim and Bo Begole, managed to build a team that is as mixed and as multicultural as ever. The conference will feature "7 Wonders," among which is "T-money," valid for real-time adjustments in choosing public transport alternatives; "K-Culture," featuring local entertainment choices; and EBS, public broadcasting dedicated to education. $\mathrm{CHI}$ attendees from the Western world will meet with an expected 700 East Asian colleagues, and we all will participate in crossing boundaries between views on HCI and styles of serving future users of technology.

- Gerrit C. van der Veer President, ACM SIGCHI 